\title{
Spend Less and Experience More: Understanding Tourists' Social Contact in the Airbnb \\ Context
}

\begin{abstract}
Emerging Airbnb accommodations provide a unique sharing economy platform where tourists can co-create their travel experiences with different participating groups. However, limited research has been conducted to understand the social contact of guests in the Airbnb accommodation. This study explores the social contact of Airbnb guests during their stay and identifies three types of contact during such stay, namely guest-host, guest-community, and guest-guest contacts. In each contact, the contact activities, intensity, and impacts, as well as attitude toward contact are discussed. A social contact model for Airbnb guests is then established. Theoretical and practical implications are provided accordingly.
\end{abstract}

Keywords: Airbnb, social contact, guest-host contact, guest-community contact, guest-guest contact.

\section{INTRODUCTION}

The incredible influence of social media on the travel industry (Fotis, Buhalis and Rossides, 2012) has led to the proliferation of social travel sites and services that provide user-generated travel reviews for travelers planning their trips. Social media has considerably affected consumer behavior, attitude, opinions, and evaluation (Mangold and Faulds, 2009). Airbnb describes itself as "a social website that connects people who have space to spare with those who are looking for a place to stay" (Zervas, Proserpio, and Byers 2014 p. 8). As an innovative means of peer-to-peer marketplace in the sharing economy, Airbnb allows "travelers to live like locals and be able to share their experience on social media" (Yung, 2014, p. 5). Guttentag (2013) identified the major factors of Airbnb that appeal to tourists. First, Airbnb accommodations are often cheaper than 
that of the traditional hotel sector which is the key factor to choose this type of service (Lin, 2019). These accommodations typically offer discounts of up to $40 \%$ off a hotel room's price (Yung, 2014). Second, local advice and authentic experiences are the highlights that differentiate Airbnb accommodations from hotel service. Travelers are looking for new and unique ways of traveling. Travelers also enjoy sharing their experiences on social media (Yung, 2014). Most successful Airbnb operations are located in urban areas, such as Paris, New York City, London, Barcelona, Sydney, Amsterdam, San Francisco, and Melbourne. The emerging popularity of Airbnb has led to increased related studies that focus on guest behaviors and experiences to provide insights into this promising market.

Social contact has gained attention in the tourism field. Cohen (1972) initially developed a fourfold tourist typology according to the degrees of familiarity and novelty in travel. By building on the work of Cohen, Fan, Zhang, Jenkins, and Tavitiyaman (2017a) explored tourists' contacts with hosts by featuring the different dimensions of contacts. Furthermore, scholars have measured social contact by considering its different dimensions (Islam and Hewstone, 1993; Huang and Hsu, 2009). In addition, the effect of social contact on the perceived cultural distance of tourists is also examined (Fan, Zhang, Jenkins and Lin, 2017b). Social oriented contact reduced the perceived cultural distance, whereas service oriented contact enlarged the perceived cultural distance between tourists and hosts.

As an emerging and popular accommodation platform, Airbnb calls for additional indepth investigations to help understand this new platform and determine how individuals behave under this unique form of accommodation. Moreover, most social contact studies have investigated the contact between tourists and hosts, whereas other kinds of contact during travel have been overlooked. Previous research has emphasized the types and measurement of social 
contact, but has scarcely explored its antecedents and consequences. The current study aims to explore the social contact between Airbnb guests and possible groups and identify a series of antecedents and consequences of the social contact.

\section{LITERATURE REVIEW}

\section{Phenomenon of sharing economy}

With the development of information technology, the attitudes of consumption have shifted to a neoliberal paradigm (Martin 2016), that is, collaborative consumption/sharing economy (Hamari, Sjöklint, and Ukkonen 2015). Sharing economy is a technological phenomenon (Hamari et al., 2015) that provides economic opportunities and sustainable forms of consumption, as well as an incoherent field of innovation (Martin 2016). Furthermore, Nica and Potcovaru (2015, p. 72) noted that the value and involvement of users in the sharing economy "make their lives easier." Similarly, Sablik (2014, p. 12) identified the benefits of a sharing economy as follows: "flexibility of supply, wide range of options, creating entirely new markets for goods and services, and additional opportunities for entrepreneurs and consumers. Correspondingly, Martin (2016, p. 15) described the sharing economy as a pathway to "a decentralized, equitable, and sustainable economy" that creates unregulated marketplaces. Roblek, Stok, and Mesko (2016) recognized sharing economy as a form of sharing the knowledge, opinions, and views of users, as well as the objects and areas of tourist activities. In addition, they also showed that it can raise the quality of service, meet the needs of guests, and increase employability. Sharing economy also enhances the destinations' response to different peak demands by offering alternative services (Cheng 2016), and it creates new opportunities for destinations (Guttentag 2013). 
The Airbnb platform is a market leader in peer-to-peer (P2P) accommodation service that provides non-commercial residents shares their spare space (Oskam and Boswijk 2016). Airbnb aims to make guests feel at home and bond with the local environment. Hosts are encouraged to treat users similar to how they treat their friends or family and share their local culture to provide guests unforgettable experiences (Liu and Mattila 2017). With convenient and trendy interfaces, Oskam and Boswijk (2016) also discuss the success factors of the Airbnb platform, including "leverage assets and empowered autonomous works, authenticity of P2P contact, and lower environmental impact." However, Richard and Cleveland (2016) indicated that P2P rental marketplaces may drive down room rates and the overall accommodation market, which is considered an unfair competition to other stakeholders.

For consumers, the sharing economy increases consumer welfare and opens new options and markets (Sablik 2014). With consumer participation, this new form of consumption is considered as a communal bond that reduces the environmental impact of consumption (Tussyadiah 2016). In addition, Nica and Potcovaru (2015) observe that the sharing economy is a way of sharing that saves resources. Oskam and Boswijk (2016, p. 16) identified three main factors that motivate participation in the sharing economy, namely, "convenience and price, the product or service itself, and word of mouth (WOM)."

Many studies (Guttentag 2013; Heo 2016; Lehr 2015; Nica and Potcovaru 2015; OECD 2016; Oskam and Boswijk 2016; Tussyadiah 2016; Weber 2014; Zervas, Proserpio, and Byers 2016) have found that Airbnb accommodations are cheaper than hotels reservations, which particularly attract to younger people, families, and people with low travel budget (Varma et al. 2016). Airbnb tourists/travelers tend to have lengthy stay and additional travel frequency that can benefit to the overall tourism industry (Cheng 2016; Fang, Ye, and Law 2016; Guttentag 2013; 
Tussyadiah 2016; Varma, Jukic, Pestek, Shultz, and Nestorov 2016; Zervas et al. 2016). Thus, Airbnb accommodations benefit local businesses and destinations. Cheng (2016) argues that the sharing economy provides benefits to middle class people seeking a high level of cultural capital rather than people in low levels of society. This type of collaborative consumption (P2P) is forecasted to expand into a large market. Key elements, such as "costs savings, familiarity, trust, and utility," positively impact the satisfaction and willingness to pursue repurchase intentions of guests (Möhlmann 2015, p. 200).

$\mathrm{P} 2 \mathrm{P}$ is a collaborative consumption pattern that fulfills the socialization needs of guests (Tussyadiah 2016). The social interaction between tourists and hosts may be considered as a key factor determining the perceived value, enjoyment (Tussyadiah 2016), and satisfaction of tourists (Heo 2016). The unique local experience (Tussyadiah and Pesonen 2015) and meaningful social encounter (Cheng 2016) highlight the differences between P2P and traditional service. By reading the "digital word-of-mouth," users have the power to make their decisions (Forno and Garibaldi 2015) and share their travel experiences. The behavior of travelers is gradually changing to a new form of consumption where $\mathrm{P} 2 \mathrm{P}$ interaction influences their planning and provides them with unique travel experiences.

Authentic local experience is one of the highlights in Airbnb accommodation service where the interaction between hosts and users is valued and emphasized by many scholars (Cheng 2016; Guttentag 2013; Heo 2016; Ikkala and Lampinen 2015; OECD 2016; Sigala 2017; Tussyadiah and Pesonen 2016). The benefit of authentic local experience includes social interaction by providing local advice (Cheng 2016) for the daily life of local residents (Guttentag 2013) in neighborhoods (Varma et al. 2016) and communities (Ikkala and Lampinen 2015). Authentic P2P contact (Oskam and Boswijk 2016) differs from ordinary hotel service where a 
standardized service is expected. The interpersonal contact among host, local residents, and community becomes a major contributor to their travel experience. Moreover, $\mathrm{P} 2 \mathrm{P}$ is also essential in expanding cultural tourism (OCED 2016), wherein users and hosts can exchange their cultural value and appreciate local culture (Sigala 2017). Airbnb also has less impact on the environment (Sigala 2017) compared with commercial means of sustainable tourism development (OCED 2016). P2P accommodation service shifts its travel pattern by providing affordable accommodation services and offering authentic social experiences to the local community (Cheng 2016). "Sharing economy generates added value by directing tourist flows beyond heavily visited tourism zones and encourage tourists to disperse to less well-known destinations" (OCED 2016, p104). In addition, "sharing economy impacts on tourists include three themes 'social,' 'behavior,' and 'members"' (Cheng 2016, p65).

\section{Social contact in tourism}

Social contact has gained attention in the tourism field. Cross-cultural social contact is the faceto-face contact between people from different cultural backgrounds (Cusher and Brislin 1996; $\mathrm{Yu}$ and Lee 2014). From a service encounter viewpoint, contacts are defined as any period when a customer interacts with a service (Shostack 1985; Bitner 1990). These kinds of contacts cover all dimensions of a service and involve diverse interactions among different parties. The general service environment has three distinct relationships, namely, customer to organization, customer to service provider, and customer to customer interactions (Yi and Gong 2009). In a service delivery system, Love and Wirtz (2004) state that a customer's experience is influenced by interactions with service personnel, physical surroundings, and other customers. 
Tourism encounter is not a particularly typical service encounter, and interactions can vary depending on the occasions and participating groups of contacts. Social contacts can be categorized by different interaction occasions. In the tourist-host context, contacts may occur when visitors purchase products, when visitors and hosts use the same place, attraction, or facility, and when they exchange information and ideas (Kastenholz, Carneiro, Eusébio, and Figueiredo 2013). Interactions between tourists and hosts can also be measured by venues where they meet each other, for instance, in food and beverage establishments, in clubs and bars, in nature places, and in events (Eusébio and Carneiro 2012). From the viewpoints of residents, Carneiro, Eusébio, and Caldeira (2017) state that three types of interactions can emerge according to the intensity of interactions, namely, close interaction, interaction at work, and interaction in attractions and facilities.

Apart from interaction occasions, contact participant groups are also widely-used criteria to categorize different types of contacts. This type of research involves various participant groups, rather than merely customers and service providers. Lovelock and Wirtz (2004) argue that interactions with service personnel, interactions with internal and external physical surroundings, and interactions with other customers may influence the overall experiences of customers. In tourism field, Choo and Petrick (2014) identify four kinds of groups involved in contacting tourists, namely, residents, other customers, service providers, and companions. Pearce (2005) recognizes that the tourism context has three types of social contacts, namely, tourist-local community, tourist-service personnel, and tourist-tourist. Literature related to each contact group for tourists will be reviewed in the following sessions. 


\section{Social contact of tourists}

Among the social contact literature, tourist-resident social contact has drawn considerable attention from the academia. Tourism provides a natural platform where tourists meet local residents and experience local cultures by interacting with the local people. This kind of contact may vary among different tourists. Cohen (1972) develops a fourfold tourist typology according to the degree of contact, namely, organized mass tourist, individual mass tourist, the explorer, and the drifter. In his work, tourist-host social contact is officially introduced to the tourism field to describe the behavior of tourists in a destination. By building on the work of Cohen, Fan et al. (2017a) explore tourists' contacts with hosts by featuring the purposes, determinants, activities, intensity, impacts, and attitude of contacts, resulting in five types of tourists, namely, dependents, conservatives, criticizers, explorers, and belonging seekers.

Shifting from interpretivism to positivism approach, numerous studies have quantified the social contact between tourists and hosts by evaluating contacts from diverse perspectives. For example, social contact activity is treated as the single measurement of social contact in the early stage of research (Rothman 1978; Mo, Howard, and Havitz 1993; Reisinger and Turner 2002a, 2002b). Contact frequency is also adapted to measure interactions between tourists and residents (Woosnam and Aleshinloye 2013). Studies have also considered multiple dimensions to measure social contact experience. The quality and frequency of interactions are used to evaluate the attitude of residents toward tourism development (Akis, Peristianis, and Warner 1996). Islam and Hewstone (1993) investigate the effects of the number of contact points, contact frequency, and contact quality on various dependent variables. Berscheid, Snyder, and Omoto (1989) consider the frequency, activity, and strength of social contact to evaluate the closeness of interpersonal relationships. In addition, the effects of social contact are also assessed for tourists 
and residents. From the viewpoint of tourists, the high intensity of the social relationship between hosts and tourists means positive change in their attitudes toward hosts and the destination (Pizam, Uriely, and Reichel 2000; Uriely and Reichel 2000). Fan et al. (2017b) examine the social oriented contact to reduce the perceived cultural distance whereas service oriented contact enlarged the perceived cultural distance between tourists and hosts. Concerning the residents of a developing destination, hosts who frequently contact tourists tend to have positive attitudes toward the interactions (Akis, Peristianis, and Warner 1996). Carneiro et al. (2017) also comment that social contact significantly affects the perceptions of residents regarding impacts of tourism on their quality of life.

Compared with the research on social contact between tourists and residents, studies on other kinds of contact are limited and mainly from the general service encounter research. The contact between customers and service providers is described as the face-to-face interaction between a buyer and a seller in a service setting (Wu 2007). This kind of service encounter strong influences the purchasing satisfaction and overall service experience of customers (Solomon, Surprenant, Czepiel, and Gutmam 1985; Lovelock 1996). Regarding the contact among fellow customers, customers are believed to affect one another indirectly by being part of the environment or directly through specific interpersonal encounters (Baker 1987; Bitner 1992). Meanwhile, fellow customers' interactions and customers' subjective interpretations and evaluations toward behaviors can greatly influence the consumption experience of customers (Fisher and Byrne 1975; Wu 2007). In the tourism setting, even less research has been established to explore the tourist-tourist social contact. $\mathrm{Wu}(2007)$ investigates the tourist-tourist interaction incidents among Taiwanese tourists and their impacts on travel experience. Another study explores how interactions between tourists in cruise ships contributed to their cruise 
experiences (Huang and Hsu 2009). Huang and Hsu (2010) examine the activity, frequency, influence, valence, intensity, power, and symmetry of customer-to-customer interactions in cruises.

\section{Attitude}

Attitude represents individuals' tendency to evaluate symbol, object, or perspective of the world in a favorable or unfavorable way (Mayo and Jarvis, 1981; Azjen, 1991). It captures great attention, especially from scholars, as it is treated as reliable indicators of how people act with a given set of conditions in different styles of life. The attitude of consumers towards their accommodations experience has been investigated in various context. In general, attitude is argued to have an effect on consumers' word-of-mouth, purchasing and sacrificing intentions (Han, Hwang, Lee and Kim, 2019). In terms of customer experience and hotel performance, customers' attitude towards various service elements determine their satisfaction and emotional attachment with hotels (Sukhu, Choi, Bujisic and Bilgihan, 2019) and will also lead to a desirable brand reputation and performance (Foroudi, 2019). Han and Yoon (2015) stated that environmental awareness and perceived effectiveness significantly affect consumers' attitudes toward the eco-friendly behavior. By analyzing the positive and negative sentiments from the Airbnb online reviews, Cheng and Jin (2019) claimed that location, amenities and host were the three main attributes of guest experience. The main concepts relating to host were found to be helpfulness, flexibility, and communication of the hosts, and the attitude of host was general positive.

The existing literature on Airbnb and social contact has raised several concerns. First, as an emerging accommodation platform, Airbnb calls for additional in-depth investigations to help 
understand this new phenomenon and how individuals behave under this unique accommodation. The interactions between tourists and various participating groups in their Airbnb experience have received minimal attention. Second, the social contact in tourism has remained insufficiently explored considering its crucial influences on different participating groups. Moreover, among those limited research in the tourism field, most studies have investigated the contact between tourists and residents, whereas other kinds of contacts that occur during travel are overlooked. Lastly, most previous studies have treated social contact as an independent concept, which affects various individual perceptions. However, factors that may influence the contact variety, intensity, or preferences of individuals with others during an experience have been rarely explored. To comprehensively understand social contact, both its antecedents and consequences should be investigated. Therefore, the current study aims to address the aforementioned research gaps by exploring the social contact between Airbnb guests and possible groups. Moreover, the antecedents and consequences of the social contact for Airbnb guests are also identified to provide implications for this industry.

\section{METHODOLOGY}

The current study followed an interpretivism paradigm, which seeks to explore reality by interpreting the truth from individuals( Veal, 2011). This research paradigm holds great merits especially when the research purpose is to explore a phenomenon during its early stage (Flick 2009). Methodologically, a qualitative research approach was adopted to examine the rich content of tourists' social contacts during their Airbnb accommodation, as well as its antecedents and consequences in the Airbnb context. Individuals who acquired accommodation experiences through the Airbnb platform in the last two years were regarded as qualified informants. To 
ensure the overall trustworthiness of this study, method triangulation, data triangulation, and investigator triangulation were considered throughout the research process to secure creditability (Lincoln and Guba 1985; Denzin 1989). For method triangulation, in-depth interviews and focus group discussions were employed to obtain data with diverse approaches. Focus groups depend on the participants' interaction to bring out similarities and differences of views, whereas individual interview is facilitated by interviewer to compare all data result. Furthermore, by using quantitative approach, Kaplowitz and Hoehn (2001, p. 245) identified that "focus groups and individual interviews are not substitutes. The information from each method was complementary, with each yielding somewhat different perspectives on the range of resource services, values, and issues.” Data triangulation was also applied by introducing different sampling methods. First, purposive sampling was used to determine eligible respondents according to the expertise and professional judgment of researchers. Second, by following snowball sampling, respondents were asked to invite people they know who qualified for this research. The interviewers stopped to invite new informants when information saturation was reached. In this study, the data analysis indicated that dimensions and patterns became stable at the 30th informant and the last 9 informants did not provide any substantive changes. As a result, 2 focus groups and 25 in-depth interviews were conducted, involving a total of 39 individuals.

The interviews and focus group discussions have three parts. First, respondents were asked about their recent accommodation experiences with Airbnb to get informants familiar with the topic. Second, after the warm-up, informants were asked to recall their experiences about their contacts with others during their Airbnb stay. Finally, informants were required to share their perceived antecedents and consequences of those contacts. According to Fan et al. (2017a), social contact can be described by contact activities and intensity. Antecedents can be 
represented by the determinants and purposes of contact. Consequences can be captured by impacts and attitudes toward contacts. The research team stopped to invite new informants when information saturation was reached. Audio files of interviews and focus group discussions were transcribed into text. Transcripts were then interpreted and analyzed using thematic analysis via

the qualitative analytical software Nvivo 11. All co-authors conducted intra-team communication regularly during the entire research process to ensure an accurate and objective coding process. Therefore, investigator triangulation was established.

\section{FINDINGS}

\section{Demographic profile of informants}

Table 1 shows the summary information of all participants' demographics in this study. Among the 39 informants, 31 are female, and 23 are single. Their ages are well distributed into different age groups with eight individuals between 18 and 25, 16 individuals between 26 and 35, ten individuals between 36 and 45, and five individuals above 45. In terms of income level, 41\% of them hold a monthly income of 10,000-20,000 HKD (1,282-2,564 USD). All informants are Chinese and based in Hong Kong, SAR, Macao, SAR, Mainland China, and Taiwan, and only a few informants are currently living in Australia and the US. The purpose of using Airbnb was all for leisure; only three informants (informant 4, 14, and 18) were for business and leisure (Bleisure). Overall, the duration of stay in Airbnb can be divided into three categories, namely, under 5 days, 6-10 days and 11 days and above which is closely related to the distance of their trips, short haul and long haul. In addition, all informants had at least use Airbnb once. An individualized demographics table for each informant is presented in Appendix 1. 
Table 1. The demographic profile of informants

\begin{tabular}{|c|c|c|}
\hline Content & $\begin{array}{c}\text { Number of } \\
\text { respondents }\end{array}$ & Percentage \\
\hline Gender & 39 & $100 \%$ \\
\hline Male & 8 & $21 \%$ \\
\hline Female & 31 & $79 \%$ \\
\hline Age & 39 & $100 \%$ \\
\hline $18-25$ & 8 & $21 \%$ \\
\hline $26-35$ & 16 & $41 \%$ \\
\hline $36-45$ & 10 & $26 \%$ \\
\hline $46+$ & 5 & $13 \%$ \\
\hline Marital Status & 39 & $100 \%$ \\
\hline Married & 10 & $26 \%$ \\
\hline Married with children & 13 & $33 \%$ \\
\hline Single & 16 & $41 \%$ \\
\hline Others & 0 & $0 \%$ \\
\hline Occupation & 39 & $100 \%$ \\
\hline Civil Servants & 1 & $3 \%$ \\
\hline Professor/Teacher/Scholar & 1 & $3 \%$ \\
\hline Self-employed & 2 & $5 \%$ \\
\hline Freelancer & 2 & $5 \%$ \\
\hline Retiree & 0 & $0 \%$ \\
\hline Office Clerk & 3 & $8 \%$ \\
\hline Worker & 0 & $0 \%$ \\
\hline Salesman & 3 & $8 \%$ \\
\hline Student & 3 & $8 \%$ \\
\hline Manager & 2 & $5 \%$ \\
\hline Housewife & 2 & $5 \%$ \\
\hline s/Engineer & 17 & $44 \%$ \\
\hline Others & 3 & $8 \%$ \\
\hline Educational Level & 39 & $100 \%$ \\
\hline Master or above & 23 & $59 \%$ \\
\hline University & 14 & $36 \%$ \\
\hline Associate Degree & 2 & $5 \%$ \\
\hline High School & 0 & $0 \%$ \\
\hline Monthly Income: (HKD) & 39 & $100 \%$ \\
\hline Below 10,000 & 5 & $13 \%$ \\
\hline $10,000-20,000$ & 16 & $41 \%$ \\
\hline $20,001-30,000$ & 6 & $15 \%$ \\
\hline $30,001-40,000$ & 4 & $10 \%$ \\
\hline $40,001-50,000$ & 1 & $3 \%$ \\
\hline Above 50,000 & 7 & $18 \%$ \\
\hline
\end{tabular}

Social contact of Airbnb guests 


\section{Contact activities and intensity}

As a unique platform providing sharing accommodation service, Airbnb enables its guests to participate in different kinds of interactions with diverse groups. First, guest-host contact is the mostly mentioned contact by Airbnb guests. As shown in Table 2, this contact type covers inquiries, casual chat, accommodation, and other personalized services, traveling or conducting activities together, dealing with problems, entertainment, reminding, and experience sharing. For example, informants indicated that "You can directly communicate with the host in Airbnb. Everything you want to know, the host will give you the firsthand information. It really makes the relationship between the host and me close. I think traditional hotels can hardly do this for their guests" (Informant 24). Second, given the convenience of Airbnb location, many guests report varying extent of interactions with residents within communities. Guests particularly have the opportunity to casually chat with locals when they go out of the Airbnb accommodation and enter the local community. "We do not look like the local people, so some residents just came to chat with us out of curiosity. They asked where we were from. Though their English is not fluent, they still wanted to communicate with us" (Informant F1). Guests may also interact with local service personnel when they use public or private services. "We rent a car and the driver introduced many local restaurants to us within our community. He also showed us around and asked us what we particularly looked for. This experience made our stay barrier-free"

(Informant F1). In addition, depending on the sharing nature of the Airbnb, guests can interact with other Airbnb guests during their stay in different ways, including casual talk, traveling together, and experience sharing. For example, one informant mentioned "We planned to go to one attraction. However, other guests told us that the place was not as good as we saw online. 
Instead, they introduced another attraction for us with fewer visitors, but better scenery. After discussing with our host, we decided to go to the one they recommended" (Informant 2).

Regarding contact intensity, the majority of contacts reported are profound. Given that this concept heavily depended on the collective view of informants, they are unable to distinguish the intensity for each type of contact. Alternatively, this concept was measured by considering all guest contacts during the Airbnb stay. "The entire experience was so impressive. My host was from Beijing, so we had something in common. She shared with me her view about how to choose a husband. Sounds interesting! The conversation was not limited to the trip itself, but covered from life, personal value to taste" (Informant F1). "My host and I discussed about the different social levels in London. As a tourist, I did not notice this. I was really impressed by his words" (Informant 18). Meanwhile, some guests thought that they had limited and superficial contacts in their destinations.

Table 2. Contact activities and intensity of Airbnb guests

\begin{tabular}{|c|c|c|}
\hline Name & Sources & References \\
\hline 1. Contact Activities & 24 & 112 \\
\hline 1.1 Guest-host contact & 24 & 94 \\
\hline 1.1.1 Enquires & 22 & 38 \\
\hline 1.1.2 Casual Chat & 8 & 13 \\
\hline 1.1.3 Accommodation service & 5 & 9 \\
\hline 1.1.4 Traveling together (showing around) & 4 & 8 \\
\hline 1.1.5 Dealing with problems & 7 & 7 \\
\hline 1.1.6 Joining host activities & 4 & 5 \\
\hline 1.1.7 Entertainment & 3 & 3 \\
\hline 1.1.8 Reminding & 1 & 1 \\
\hline 1.1.9 Experience sharing & 1 & 1 \\
\hline 1.1.10 Other personalized service & 7 & 9 \\
\hline 1.2 Guest-community contact & 8 & 12 \\
\hline 1.2.1 Casual chat & 3 & 5 \\
\hline 1.2.2 Enquires & 4 & 4 \\
\hline 1.2.3 Local activities participation & 2 & 2 \\
\hline 1.2.4 Transportation service & 1 & 1 \\
\hline 1.3 Guest-guest contact & 3 & 6 \\
\hline 1.3.1 Casual chat & 2 & 2 \\
\hline
\end{tabular}




\begin{tabular}{crr}
\hline 1.3.2 Traveling together & 2 & 2 \\
1.3.3 Sharing experience & 1 & 2 \\
2. Contact intensity & 13 & 31 \\
2.1 Profound & 13 & 24 \\
2.2 Superficial & 4 & 7 \\
\hline
\end{tabular}

\section{Contact determinants and purposes}

In the current study, contact determinants generally covered factors that can facilitate or constrain face-to-face interactions. Determinants were further classified into those of general and particular contacts. Table 3 shows that language competence, mismatched schedule and distanced neighbors, legal, political or cultural sensitivity, cultural difference, and communication competence of travel companions were identified as main factors that influence all kinds of contacts during the stay in Airbnb. Some informants mentioned that language was the biggest concern when communicating with locals. "We stayed in a small village in France for several days. Everyone knew everyone there. The host recommended a restaurant for us. However, given that the restaurant owner did not speak English, our conversation got stuck at the choices of pork or fish and we could not move on" (Informant F1). Sensitive topics were also avoided by guests to maintain positive relationships with hosts in particular destinations. "It was like a gap. I am from Mainland China. When I traveled to Taiwan, I tried to avoid giving any opinions or raising any topics on the relationship between the two regions. In that case, we only talked about the food, the weather and something quite shallow" (Informant F1).

In terms of guest-host contact, characters or taste of hosts, sharing an apartment with the hosts, interesting activities, potential business opportunities, and something in common are the determinants. For example, "Our hosts were very out-going and friendly persons. They liked tourists and had great interest to know more about us and what happened in our countries" 
(Informant F1). "Our host owned his farm. We had many activities to join in every day, such as catching fish, shooting birds, herding sheep, and feeding chicks. It was lots of fun!' (Informant 18). When communicating within the community, the local character, and the security situation influence interactions. "It depends on the local security situation. If I travel in a secure destination, I may have more contacts with locals. Otherwise, I may be very protective and do not proactively communicate with others" (Informant F1). When guests interact with their peer guests, only the character of other guests is reported to influence their contact.

Individuals contact others with different internal desires. As an Airbnb guest in a destination, the majority of contacts are to seek information or help from hosts. "The host can give you very useful information according to your own interest and the location of the apartment. For example, our host in Paris told us how to get to the place we planned to go, by bus, by taxi, or by walking. Such kind of tailor-made travel information can hardly be found elsewhere" (Informant 10). Apart from inquires, Airbnb guests also contact their hosts for social purposes. From the interviews, guests chat with their hosts as close friends because they live together and see each other daily. The favorable nature of the relationship and the sharing nature of Airbnb encourage these kinds of close interactions between the two parties. In addition, guests also contact their hosts to solve problems, explore destinations, and share travel experiences.

Similarly, when Airbnb guests visit the community, they intend to interact with locals to ask for information, explore the local culture and lifestyle, socially chat with locals, share their travel experiences, and solve any problem. When guests come back from their travel, they meet their peer guests within the same Airbnb unit. On such occasions, they want to share their travel experiences and leisurely chat with each other.

Table 3. Contact determinants and purposes of Airbnb guests 


\begin{tabular}{|c|c|c|}
\hline Name & Sources & References \\
\hline 3. Determinants of contact & 22 & 93 \\
\hline 3.1 General contact & 10 & 22 \\
\hline 3.1.1 Language competence & 8 & 12 \\
\hline 3.1.2 Mismatched schedule and distanced neighbors & 9 & 11 \\
\hline 3.1.3 Legal, political or cultural sensitivity & 3 & 6 \\
\hline 3.1.4 Cultural difference & 2 & 3 \\
\hline 3.1.5 Communication competence of travel companions & 1 & 1 \\
\hline 3.2 Guest-host contact & 19 & 58 \\
\hline 3.2.1 Character or taste of hosts & 18 & 42 \\
\hline 3.2.2 sharing apartment with the hosts & 6 & 9 \\
\hline 3.2.3 Interesting activities & 2 & 3 \\
\hline 3.2.4 Potential business opportunities & 1 & 2 \\
\hline 3.2.5 Something in common & 2 & 2 \\
\hline 3.3 Guest-community contact & 4 & 7 \\
\hline 3.3.1 Character of locals & 4 & 6 \\
\hline 3.3.2 Security of destination & 1 & 1 \\
\hline 3.4 Guest-guest contact & 4 & 6 \\
\hline 3.4.1 Character of other guests & 4 & 6 \\
\hline 4. Purposes of contact & 26 & 99 \\
\hline 4.1 Guest-host contact & 26 & 88 \\
\hline 4.1.1 Seeking for information or help & 23 & 57 \\
\hline 4.1.2 Social interaction & 8 & 14 \\
\hline 4.1.3 Problem solving & 7 & 9 \\
\hline 4.1.4 Exploring the destination (local culture and life) & 4 & 4 \\
\hline 4.1.5 Experience sharing & 3 & 3 \\
\hline 4.1.6 Others & 1 & 1 \\
\hline 4.2 Guest-community contact & 8 & 9 \\
\hline 4.2.1 Seeking for information or help & 3 & 3 \\
\hline 4.2.2 Exploring the destination (local culture and life) & 2 & 2 \\
\hline 4.2.3 Social interaction & 2 & 2 \\
\hline 4.2.4 Experience sharing & 1 & 1 \\
\hline 4.2.5 Problem solving & 1 & 1 \\
\hline 4.3 Guest-guest contact & 1 & 2 \\
\hline 4.3.1 Experience sharing & 1 & 1 \\
\hline 4.3.2 Social interaction & 1 & 1 \\
\hline
\end{tabular}

\section{Contact impacts and attitude}

Consistent with the literature, social contacts influence individuals differently. Informants

mentioned that social contacts in the destination, regardless of contact parties, generally reinforce their experiences of the local lifestyle, customs, and cultural features. "During the talk with the 
host's son, I had a better understanding of the local culture and lifestyle. I mean it is a very indepth understanding. This is the advantage of staying in the local's house and living with them. I believe traditional hotels can hardly provide such experience for me" (Informant 3). Guests also gained knowledge during interactions and perceived to learn something from the trip. "Our host made welcome cakes for us. She was an expert in cooking and had high standards in food. She also shared her knowledge on how to taste wine. My feeling is, sometimes we only live within our own circle or frame. Traveling with Airbnb and contacts with other people definitely broadened my horizon. I have the opportunity to discover others' lives and to know something I could never know when I stay inside my own frame" (Informant 26). Some guests even stated that contacts with hosts and locals help change their original perceptions toward the destination and its residents.

Regarding the guest-host contact particularly, after their interaction experience, they expressed the intention to recommend this Airbnb service to their friends and relatives. Some informants also considered revisiting in the near future or settling in the destination. After the in-depth understanding of the place and its people, some guests established a strong sense of belonging to the place and to the host family. "This is like a home away from home. After the first visit, I always went back to the same place. I bought sheep and left them in their farm. I also brought my dog there. The host helped me feed them. He also informed me when my sheep gave birth" (Informant 18).

Regardless of the types of contact, most informants indicated that their interactions in the destinations were positive. The terms "enjoyable," "useful," "informative," and "impressive" were used by informants in describing their contacts. One negative case was found regarding the contact with the Airbnb host. "When we just arrived at the place, the host started to count how 
many of us would stay to make sure that the guest number was the same as booked. He then reminded us of many rules in his apartment, for instance, remembering to shut down the air conditioner upon leaving and being careful of some decorations in the room. It made us feel uncomfortable. We were not trusted at all" (Informant 16).

Table 4. Contact impacts and attitudes of Airbnb guests

\begin{tabular}{lrr}
\hline \multicolumn{1}{c}{ Name } & Sources & References \\
\hline 5. Contact impacts & 17 & 57 \\
5.1 Guest-host contact & 16 & 52 \\
5.1.1 Reinforcing local features or customs & 14 & 28 \\
5.1.2 Self-improvement & 5 & 6 \\
5.1.3 Recommendations to others & 3 & 4 \\
5.1.4 Changing images of destinations and local people & 3 & 3 \\
5.1.5 Sense of belonging & 2 & 3 \\
5.1.6 Revisit or immigrant intention & 2 & 2 \\
5.1.7 Recommendations for the specific trip (short term) & 1 & 2 \\
5.1.8 Enhancing the cross-cultural competence & 1 & 1 \\
5.1.9 Recommendations for future travel plans (long term) & 1 & 1 \\
5.1.10 Willingness to learn more and stay longer & 1 & 1 \\
5.1.11 Making friends & 1 & 1 \\
5.2 Guest-community contact & 4 & 5 \\
5.2.1 Reinforcing local features or customs & 2 & 2 \\
5.2.2 Self improvement & 2 & 2 \\
5.2.3 Changing images of destinations and local people & 1 & 1 \\
6. Attitude towards contact & 15 & 31 \\
6.1 Positive & 14 & 29 \\
6.2 Negative & 1 & 1 \\
6.3 Neutral & 1 & 1 \\
\hline
\end{tabular}

\section{DISCUSSION AND IMPLICATIONS}

As an innovative platform of P2P sharing accommodation, Airbnb enables its guests to experience various unique contacts with different parties in the destination. A social contact model for Airbnb guests is established by identifying the different types of social contacts encountered by Airbnb guests; this model demonstrates the formation process of social contact and its antecedents and consequences (Figure 1). First, the guest-host contact is commonly 
encountered when they stay in Airbnb accommodation. Given the sharing nature of the Airbnb platform, guests stay in the spare apartments of locals and have the chance to meet their hosts. Some guests share the same unit with their hosts, whereas others live close to their hosts. Under this circumstance, guests interact with their hosts to familiarize themselves with the place, to inquire about the accommodation service and travel information, to solve problems, or to simply get to know each other. In some cases, hospitable hosts may invite their guests to travel together or to join their own family and entertainment activities. This kind of contact is generally profound and positive to guests. Language competence, schedule of hosts, political or cultural sensitivity, and communication competence of travel companions determine the extent of guesthost social contact. The contact is also influenced by the characters and tastes of hosts, activity participation, and further business opportunity. For the purposes of contact, most guests prefer to contact their hosts for travel information and accommodation services. Some guests may also interact with their hosts for social purposes, such as casual chats, to explore local culture and customs and to share their travel experiences. Consequently, Airbnb guests obtain an in-depth understanding of local features and customers by contacting their hosts. They also indicated the intention to revisit in the future, to recommend Airbnb to their friends and relatives, and even want to immigrate to the destination. By interacting with the hosts, guests also learn something from their hosts and feel a sense of belonging to the place. The findings are consistent with the existing literature on contacts between customers and service providers (Solomon et al. 1985; Lovelock 1996; Wu 2007), which has argued that interactions between two parties can influence the entire service experiences of consumers.

The second type of social contact encountered by Airbnb guests is the guest-community contact. Airbnb users not only share their spare spaces with their hosts, but also share the same 
community with the local people as most of the Airbnb accommodations are embedded in the residential areas of a destination. This sharing nature ensures that guests have the same travel experience as the locals. When going out of the Airbnb, guests can meet community residents and communicate with them directly. Their interactions with the community include casual chatting with residents, asking travel information, participating in local activities, and communicating with local bus or taxi drivers. Although the contact variety is limited, this kind of contact tends to be profound and positive. Compared with traditional hotel guests, Airbnb guests can easily access non-tourism areas and connect with locals. This kind of experience is perceived to be authentic. Similar to the guest-host contact, language, cultural, and political sensitivity, and communication competence of travel companions may influence the individuals' extent of contact with the community. The character of local people and the security situation of a destination also determine the contact of guests with the community. Contact purposes are similar to the guest-host contact and both social and service-oriented contacts are engaged. Considering the impacts, guests reported that this kind of contact might reinforce local features and customs, facilitate self-improvement, and change the original images of the local people and the destination. Previous studies on tourist-host social contact have mainly referred to the guestcommunity contact in the current study. However, compared with mass tourists, Airbnb guests can explore the back stage of a tourism destination and contact non-tourism related residents in their communities. This unique nature creates an authentic and meaningful experience for guests and responds to the Airbnb slogan "Experience a city like a local."

The last type of contact by Airbnb guests is the guest-guest contact. Compared with the first two types, guest-guest social contact occurs less frequently and depends on the property type. This kind of social contact fundamentally differs from that with hosts and the community. 
Both host and community are destination-based, whereas peer guests are also destination visitors; thus, they share similar identities and interests. Their contact mostly relates to social and casual chat, traveling together, and sharing each other's experience. As mentioned in the interviews, apart from language, schedule, cultural, and political sensitivity, the cultural difference and communication competence of travel companions and character of peer guests are important factors influencing their contact. Their contact purpose is to socialize and share experiences with other guests. Although no particular impact is identified from this type of social contact, the attitude toward this contact is positive.

**Insert Figure 1. The conceptual framework of social contact among Airbnb guests

With a reasonable rate, Airbnb not only provides guests with a completely new accommodation experience but also a unique travel experience. Compared with traditional hotel guests, Airbnb guests are involved in additional social contacts with different groups. Guests commonly have direct contact with their hosts for first-hand travel and accommodation information. When they go out, they immediately enter the local community where local people live and work. They discover the authentic life of locals by observing and interacting with them. After the visit, guests come back to their Airbnb place and share their experiences with other peer guests in the same property. This kind of travel style nurtures a high level of tourist engagement with the destination. Considering mass tourists, especially package tourists who encapsulate themselves within a tourist bubble with limited contact with the local environment and residents, Airbnb guests have additional personal and intensive interactions in destinations and generate positive attitudes toward destinations and locals. Meanwhile, interacting with different groups also create a caring, hospitable, and pleasant atmosphere for tourists. Therefore, 
Airbnb guests tend to have additional influences by this type of contact. One example is that in some cases, the Airbnb experiences of tourists made them consider immigrating to the destination in the future, which is rarely experienced by mass tourists.

\section{Theoretical and practical contributions}

The current study generates theoretical insights, the most salient of which is that it pioneers the exploration of social contact acquired by Airbnb guests in a destination. Due to the insufficiency of in-depth and focused investigations in social contact of Airbnb guests, the importance of the host-guest interaction is questioned (Cheng and Foley, 2018; Cheng and Jin, 2019). Current findings reveal that there is a rich variety of contact activities between Airbnb guests and the host, community and other guests. Those social interactions could generate different impacts on guests' travel experience, personal actualization and sense of travel confidence. It is also noted that the majority of the informants reported a positive attitude towards the contacts in Airbnb stay, which confirms the importance of social contact in Airbnb context. However, contact determinants and purposes should also be considered when evaluating the role of social contact in Airbnb guests' experience. Second, this study $r$ identified three types of contact, namely, guest-host, guest-community, and guest-guest contacts. Considering the existing social contact literature in tourism, which has mainly focused on the tourist-community social contact in a destination (Woosnam and Aleshinloye 2013; Fan et al. 2017a), findings expand the existing body of knowledge by introducing guest-host and guest-guest contacts. The development from unidimensional to multidimensional contact enriches our existing understanding of the Airbnb guest behavior in a destination. Building on this understanding, the study may further facilitate academics to investigate why and how the behavior of Airbnb guests influences the normal life of residents, as reported in some of the European destinations (Haines 
2016). Moreover, this research also explores various antecedents and consequences of the Airbnb social contact, which provides a good theoretical base for future quantitative research.

The study also offers practical implications for different stakeholders in a destination. From this study, Airbnb guests contact hosts for any travel or accommodation information. A pleasant contact may engage guests with the Airbnb place and even the destination. This engagement will encourage tourists to revisit the Airbnb place and recommend it to their friends and relatives in the future. Findings help Airbnb hosts understand the behavioral patterns and preferences of their guests. With this information, hosts can improve their preparation for the arrival of guests and nurture a pleasant interaction with them. For example, offering a comprehensive travel guide and guest user manual can assist guests to have a smooth travel experience as well as fit into the local community easily. Findings also inform government officials of the destination on how to establish a positive destination image by engaging communities and Airbnb owners and how to maintain a sustainable tourist-resident relationship. In Taiwan, the local tourism department often organizes small workshops for bed and breakfast hosts to provide appropriate hospitality service. Similarly, if local government recognizes this trend of informal accommodation development, a series of training courses can be provided to all hosts to enhance their service standard. The support of local communities is a vital component to the success of maintaining a good relationship with tourists. The government can consider improving the awareness of residents regarding tourism by continuous education. This kind of education not only informs hosts about the benefits tourism brings, but also the behavioral and perceptional differences that residents may experience given their different cultural backgrounds. With a tolerant and considerable hosting environment, a positive tourist-host relationship can be naturally nurtured. As an emerging stakeholder in the tourism sector, Airbnb hosts are important 
in building a positive destination image and cultivating the revisit intentions of tourists. In addition, basic host training can be carried out by relevant organizations or directly by regional Airbnb branches to provide timely and useful information about being a good host and setting up a basic service standard for hosts. Meanwhile, given the increasing awareness on the disturbing effect of Airbnb phenomenon, related organizations must closely monitor the development of Airbnb in each community to balance the economic benefit and social welfare of residents. In Amsterdam and London, Airbnb has agreed to take responsibility of policing limits on the number of days per year a full unit can be let through its system, making it the first short-term rental company to cut such a deal (Woolf 2016). The recent practice of Amsterdam and London sheds lights on how to secure the balance between the rights of local people and the overwhelmed Airbnb through policies and regulations.

Based on the findings of three types of contact, this study also suggests that reinforcing local features or customs is the key element for both guest-host contact and guest-community contact. It may also shed lights on how local government can assist residents to foster their local tradition and culture. However, it is noticed that some informants used Airbnb service in city locations of Japan, Thailand and the US, where they did not meet with Airbnb hosts during their stays. Some Airbnb accommodations are considered as pure investments which are operated by agents to offer standardized house rules and are not supporting much social interaction with guests. Thus, the level of social contact may depend on if the host intend to treat this service as an investment or as a platform to provide an authentic experience. Lastly, many informants mentioned about the impacts of social contact on destination image. With a positive experience, the traveler can change the image of destinations and local people positively. Meanwhile, with the image of a friendly and safe destination, tourists feel confident to use Airbnb and experience 
the local culture. Thus, it is suggested that destination marketing organizations can consider Airbnb as a way of enhancing their destination images. Encouraging Airbnb guests to share their personal touches, surprising moment, and social experiences via WOM or e-WOM can be an effective way to market a destination.

\section{CONCLUSION AND LIMITATIONS}

"To experience a city like a local," Airbnb provides a unique sharing economy platform where tourists can co-create travel experiences with different participating groups. Given its sharing nature, Airbnb highlights the interactive element during the travel of tourists. However, empirical research emphasizing the social contact of Airbnb guests in a destination has remained scarce. By adopting a qualitative research approach, this study explored the social contact of Airbnb guests and identified three types of contact during their stay, namely, guest-host, guestcommunity, and guest-guest contacts. In each contact, contact activities, intensity, determinants, purposes, and impacts, as well as the attitude toward contact were discussed. Theoretically, this study explored the social contact Airbnb guests acquire in a destination and considered guesthost and guest-guest contacts. This research explores various antecedents and consequences of the Airbnb social contact, which opens opportunities for future quantitative research. Meanwhile, this study also offers practical implications for Airbnb owners and tourism planners to jointly cultivate a positive travel experience and destination image, high revisit intention, and sustained tourist-host relationship.

Similar to other studies, this research has its limitations. As Airbnb is an online based accommodation platform, most Airbnb users not only contact their hosts upon arrival, but also approach them even before the trip. As this study focuses on the face-to-face social contact of the 
Airbnb guests, the online pre- and post-trip communication with hosts are excluded. The cultural background of the informants may limit current implications within the eastern markets, and the western Airbnb guests' perceptions and behaviors may be different due to the cultural difference. In addition, a considerable of Airbnb guests and hosts do not care about social interaction in this informal accommodation service. Mainly, some Airbnb operations are managed by professional real estate service which they do not intent to create social interaction with guests. Further studies are encouraged to explore guests' extended online contacts and to replicate in different markets, in order to add insights to understanding the experiences of different guests. In addition, adopting a quantitative approach to investigate the causal relationship among the six contact dimensions holds its merits to supplement the current qualitative findings and connect the Airbnb phenomenon with a broad tourism development agenda.

\section{References}

Ajzen, I. (1991). The theory of planned behavior, Organizational Behavior and Human Decision Processes, 50, 179-211.

Akis, S., Peristianis, N., \& Warner, J. (1996). Residents' attitudes to tourism development: the case of Cyprus. Tourism Management, 17(7), 481-494.

Baker, J. (1987). The services challenge: integrating for competitive advantage. American Marketing Association, Chicago, IL, 79-84.

Berscheid, E., Snyder, M., \& Omoto, A. M. (1989). The Relationship Closeness Inventory: Assessing the closeness of interpersonal relationships. Journal of personality and social psychology, 57(5), 792.

Bitner, M. J. (1990). Evaluating service encounters: the effects of physical surroundings and employee responses. The Journal of Marketing, 69-82.

Bitner, M. J. (1992). Servicescapes: The impact of physical surroundings on customers and employees. The Journal of Marketing, 57-71.

Carneiro, M. J., Eusébio, C., \& Caldeira, A. (2017). The Influence of Social Contact in Residents' Perceptions of the Tourism Impact on Their Quality of Life: A Structural Equation Model. Journal of Quality Assurance in Hospitality \& Tourism, 1-30.

Cheng, M., \& Foley, C. (2018). The sharing economy and digital discrimination: The case of Airbnb. International Journal of Hospitality Management, 70, 95-98. 
Cheng, M., \& Jin, X. (2019). What do Airbnb users care about? An analysis of online review comments. International Journal of Hospitality Management, 76, 58-70.

Choo, H., \& Petrick, J. F. (2014). Social interactions and intentions to revisit for agritourism service encounters. Tourism Management, 40, 372-381.

Cohen, E. (1972). Toward a sociology of international tourism. Social research, 164-182.

Cushner, K., \& Brislin, R. W. (1996). Intercultural interactions: A practical guide (Vol. 9): Sage publications.

Denzin, N. K. (1989). Interpretive biography (Vol. 17): Sage.

Eusébio, C. A., \& Carneiro, M. J. A. (2012). Determinants of tourist-host interactions: an analysis of the university student market. Journal of Quality Assurance in Hospitality \& Tourism, 13(2), 123-151.

Fan, D. X., Zhang, H. Q., Jenkins, C. L., \& Lin, P. M. (2017). Does Tourist-Host Social Contact Reduce Perceived Cultural Distance? Journal of Travel Research, 0047287517696979.

Fan, D. X., Zhang, H. Q., Jenkins, C. L., \& Tavitiyaman, P. (2017). Tourist typology in social contact: An addition to existing theories. Tourism Management, 60, 357-366.

Fisher, J. D., \& Byrne, D. (1975). Too close for comfort: Sex differences in response to invasions of personal space. Journal of personality and social psychology, 32(1), 15.

Flick, U. (2014). An introduction to qualitative research: Sage.

Foroudi, P. (2019). Influence of brand signature, brand awareness, brand attitude, brand reputation on the hotel industry's brand performance. International Journal of Hospitality Management, 76, 271-285.

Fotis, J., Buhalis, D., \& Rossides, N. (2012). Social Media Impact on Holiday Travel Planning: The Case of the Russian. Transdisciplinary Marketing Concepts and Emergent Methods for Virtual Environments, 230.

Guttentag, D. (2013). Airbnb: disruptive innovation and the rise of an informal tourism accommodation sector. Current Issues in Tourism(ahead-of-print), 1-26.

Haines, G. (2016). Amsterdam has become 'unlivable' as residents fight back to stop 'Disneyfication' of city. Retrieved from http://www.telegraph.co.uk/travel/destinations/europe/netherlands/amsterdam/articles/ho w-amsterdam-is-tackling-disneyfication/

Han, H., \& Yoon, H.J. (2015). Hotel customers' environmentally responsible behavioral intention: Impact of key construct on the decision in green consumerism. International Journal of Hospitality Management, 45, 22-33.

Han, H., Hwang, J., Lee, M.J., \& Kim, J. (2019). Word-of-mouth, buying, and sacrifice intentions for eco-cruises: exploring the function of norm activation and value-attitudebehavior. Tourism Management, 70, 430-443.

Huang, J., \& Hsu, C. H. (2009). Interaction among fellow cruise passengers: Diverse experiences and impacts. Journal of Travel \& Tourism Marketing, 26(5-6), 547-567.

Huang, J., \& Hsu, C. H. (2010). The impact of customer-to-customer interaction on cruise experience and vacation satisfaction. Journal of Travel Research, 49(1), 79-92. 
Islam, M. R., \& Hewstone, M. (1993). Dimensions of contact as predictors of intergroup anxiety, perceived out-group variability, and out-group attitude: An integrative model. Personality and Social Psychology Bulletin, 19(6), 700-710.

Kastenholz, E., Carneiro, M. J., Eusébio, C., \& Figueiredo, E. (2013). Host-guest relationships in rural tourism: evidence from two Portuguese villages. Anatolia, 24(3), 367-380.

Lin, P. M. (2018). Is Airbnb a Good Choice for Family Travel?. Journal of China Tourism Research, 1-18.

Lincoln, Y. S., \& Guba, E. G. (1985). Naturalistic inquiry (Vol. 75): Sage.

Lovelock, C. H., \& Wirtz, J. (2004). Service marketing (5th ed.). Englewood Cliffs, NJ: PrenticeHall.

Möhlmann, M. (2015). Collaborative consumption: determinants of satisfaction and the likelihood of using a sharing economy option again. Journal of Consumer Behaviour, 14(3), 193-207. doi:10.1002/cb.1512

Mangold, W. G., \& Faulds, D. J. (2009). Social media: The new hybrid element of the promotion mix. Business Horizons, 52(4), 357-365.

Mayo, E. J. \& Jarvis, L. P. (1981). The psychology of leisure travel: Effective marketing and selling of travel services. Boston: CBI Publishing Company Inc.

Mo, C.-m., Howard, D. R., \& Havitz, M. E. (1993). Testing an international tourist role typology. Annals of Tourism Research, 20(2), 319-335.

Pearce, P. L. (2005). Tourist behaviour: Themes and conceptual schemes (Vol. 27): Channel View Publications.

Pizam, A., Uriely, N., \& Reichel, A. (2000). The intensity of tourist-host social relationship and its effects on satisfaction and change of attitudes: the case of working tourists in Israel. Tourism Management, 21(4), 395-406.

Reisinger, Y., \& Turner, L. W. (2002a). Cultural differences between Asian tourist markets and Australian hosts, Part 1. Journal of Travel Research, 40(3), 295-315.

Reisinger, Y., \& Turner, L. W. (2002b). Cultural differences between Asian tourist markets and Australian hosts: Part 2. Journal of Travel Research, 40(4), 385-395.

Rothman, R. A. (1978). Residents and transients: Community reaction to seasonal visitors. Journal of Travel Research, 16(3), 8-13.

Shostack, G. L. (1985). Planning the service encounter. The service encounter, 1, 243-254.

Solomon, M. R., Surprenant, C., Czepiel, J. A., \& Gutman, E. G. (1985). A role theory perspective on dyadic interactions: the service encounter. The Journal of Marketing, 99111.

Sukhu, A., Choi, H., Bujisic, M., \& Bilgihan, A. (2019). Satisfaction and positive emotions: A comparison of the influence of hotel guests' beliefs and attitudes on their satisfaction and emotions. International Journal of Hospitality Management, 77, 51-63.

Uriely, N., \& Reichel, A. (2000). Working tourists and their attitudes to hosts. Annals of Tourism Research, 27(2), 267-283.

Veal, A. J. (2006). Research methods for leisure and tourism: A practical guide: Pearson Education.

Veal, A. J. (2011). Research Methods for Leisure and Tourism: a Practical Guide. Harlow Financial Times Prentice Hall. 
Woolf, N. (2016). Airbnb Regulation Deal With London and Amsterdam Marks Dramatic Policy Shift. The Guardian, 3.

Woosnam, K. M., \& Aleshinloye, K. D. (2013). Can tourists experience emotional solidarity with residents? Testing Durkheim's model from a new perspective. Journal of Travel Research, 52(4), 494-505.

Wu, C. H.-J. (2007). The impact of customer-to-customer interaction and customer homogeneity on customer satisfaction in tourism service- the service encounter prospective. Tourism Management, 28(6), 1518-1528.

Yi, Y., \& Gong, T. (2009). An integrated model of customer social exchange relationship: the moderating role of customer experience. The Service Industries Journal, 29(11), 15131528.

Yu, J., \& Lee, T. J. (2014). Impact of tourists' intercultural interactions. Journal of Travel Research, 53(2), 225-238.

Yung, V. (2014). My Airbnb year in Hong Kong: 'Big fat American' discovers hidden sides to the city. South China Post. Retrieved from http://www.scmp.com/print/lifestyle/travel/article/1656453/expat-explores-hong-kongyear-short-term-stays-through-airbnb 